\title{
A SATELLITE EXPERIMENT TO MEASURE THE INTENSITY

\author{
AND THE ENERGY SPECTRUM OF GAMMA RAYS FROM \\ SOLAR FLARES IN THE RANGE 50-500 MeV
}

G. F. BIGNAMI, C. J. BLAND*, O. CITTERIO, A. J. DEAN, and P. INZANI Università Degli Studi di Milano, Istituto di Scienze Fisiche, Milano, Italy

\begin{abstract}
A high energy solar gamma-ray telescope incorporating a lenticular Cerenkov for directional measurement and an energy calorimeter is described. The instrument is included in the payload of the TD-1 ESRO spacecraft to be launched into a sun-pointing orbit during spring 1972. The results of laboratory and accelerator tests are presented and the sensitivity and measurement capability to solar flare gamma rays is discussed.
\end{abstract}

